\title{
Radiosurgery with a Rotating Gamma System: A Very Effective Treatment for Symptomatic Cerebral Cavernomas
}

\author{
PHAM CAM PHUONG ${ }^{1}$, NGUYEN DUC LUAN ${ }^{1}$, VO THI HUYEN TRANG ${ }^{1}$, \\ STEVEN E. SCHILD ${ }^{2}$, DIRK RADES ${ }^{3,4}$ and MAI TRONG KHOA ${ }^{1,4}$ \\ ${ }^{1}$ The Nuclear Medicine and Oncology Center, Bach Mai Hospital, Hanoi, Vietnam; \\ ${ }^{2}$ Department of Radiation Oncology, Mayo Clinic, Scottsdale, AZ, U.S.A.; \\ ${ }^{3}$ Department of Radiation Oncology, University of Lübeck, Lübeck, Germany; \\ ${ }^{4}$ Department of Nuclear Medicine, Ha Noi Medical University, Hanoi, Vietnam
}

\begin{abstract}
Aim: To evaluate the value of radiosurgery with a rotating gamma-system (RGS) for cerebral cavernomas. Patients and Methods: Seventy-nine patients with symptomatic cerebral cavernomas underwent $R G S$ radiosurgery at the Bach Mai Hospital, Hanoi, Vietnam. Median dose (single fraction) was 20 Gy (range=14-26 Gy). Endpoints included effect on headache, seizures and tumor size. Results: Of 60 patients with headache, $17 \%$ had complete response, $82 \%$ partial response and $2 \%$ stable disease (best response). Of 39 patients with seizures, $31 \%$ had complete response, $64 \%$ partial response and $5 \%$ stable disease. Four patients developed recurrent seizures after 1 year. Regarding the size of cavernoma at 15 months, complete response was observed in $6 \%$, partial response in $75 \%$, stable disease in $15 \%$, progression in $1 \%$ and pseudo-progression in 3\% of patients. Bleeding within 2 years after RGS radiosurgery occurred in only five patients (6\%). $R G S$ dose had no significant impact on outcomes. Conclusion: $R G S$ radiosurgery provided very high rates of symptom relief in patients with cerebral cavernomas.
\end{abstract}

Cerebral cavernomas are cavernous malformations of the vascular bed (1). These tumors account for about $10-25 \%$ of all cerebrovascular malformations (2). In the general population, the incidence of cerebral cavernomas is less than $1 \%$. About $75 \%$ of such lesions are located supra-tentorially and are often associated with headache and seizures. Intracerebral bleeding is also quite common.

Correspondence to: Pham Cam Phuong, MD, Ph.D., The Nuclear Medicine and Oncology Center, Bach Mai Hospital, 78 Giai Phong Street, Dong Da, Ha Noi, 100 000, Vietnam. Tel: +84 983920778 , e-mail: phamcamphuong@gmail.com

Key Words: Cerebral cavernoma, radiosurgery, Rotating-Gamma System, headache, seizures, symptom relief, cavernous hemangioma, cavernous angioma.
At many centers, microsurgical resection is considered standard treatment approach for cerebral cavernomas (2). Optimal clinical outcome requires complete resection of the cavernoma. Subtotal resection is associated with subsequent episodes of bleeding in approximately $40 \%$ of cases (2). Therefore, only very experienced neurosurgeons should perform resection of cerebral cavernomas. Moreover, neurosurgical resection cannot be recommended for lesions in the brainstem or other eloquent areas of the brain, since it may result in significant morbidity. For these patients, stereotactic radiosurgery represents a reasonable alternative. Several studies have shown that radiosurgery is safe and effective for lesions not amenable to neurosurgery (3).

Several types of radiosurgery are available for the treatment of cerebral cavernomas, including mainly linear accelerator-based radiosurgery and gamma-ray based radiosurgery techniques $(1,4-6)$. Currently, two different gamma-ray based systems are available. The classic Gamma-Knife consists of 201 concentric cobalt-60 sources and has been used since 1968 for intracerebral lesions (7). About 30 years later, the Rotating Gamma System (RGS) system was introduced (8). This device combines features of both the traditional Gamma-Knife and linear acceleratorbased radiosurgery. Our present study is the second study evaluating the role of RGS-radiosurgery for the cerebral cavernomas.

\section{Patients and Methods}

Seventy-nine patients underwent radiosurgery for a supra-tentorial cavernoma with RGS at the Nuclear Medicine and Oncology Center of the Bach Mai Hospital in Hanoi, Vietnam, between July, 2007 and May, 2015. The median age of these patients was 34 years (range $=8-79$ years). Thirty-nine patients were female, and 40 patients were male. The tumor was in the following lobes: temporal in 33 patients, frontal in 20, occipital in nine, parietal in 9 patients and other sites in eight. In all 79 patients, the cavernoma bled, 
Table I. Subgroup analysis: Response rates related to different doses of Rotating Gamma-System radiosurgery ( $<20$ Gy vs. 20 Gy vs. $>20$ Gy). Complete response was defined as complete relief of symptoms or complete disappearance of the cavernoma. Overall response was defined as complete or partial symptom relief or decrease of the cavernoma in size. p-Values were calculated with the Chi-square test.

\begin{tabular}{|c|c|c|c|c|c|}
\hline \multirow[b]{2}{*}{ Endpoint } & \multirow[b]{2}{*}{ Response } & \multicolumn{4}{|c|}{ Radiation } \\
\hline & & $<20 \mathrm{~Gy}$ & $20 \mathrm{~Gy}$ & $>20 \mathrm{~Gy}$ & $p$-Value \\
\hline \multirow[t]{2}{*}{ Headache } & Complete & $8 \%(2 / 24)$ & $23 \%(5 / 22)$ & $21 \%(3 / 14)$ & 0.43 \\
\hline & Overall & $100 \%(24 / 24)$ & $95 \%(21 / 22)$ & $100 \%(14 / 14)$ & 0.99 \\
\hline \multirow[t]{2}{*}{ Seizures } & Complete & $22 \%(4 / 18)$ & $50 \%(7 / 14)$ & $14 \%(1 / 7)$ & 0.25 \\
\hline & Overall & $94 \%(17 / 18)$ & $100 \%(14 / 14)$ & $86 \%(6 / 7)$ & 0.96 \\
\hline \multirow[t]{2}{*}{ Cavernoma size } & Complete & $6 \%(2 / 35)$ & $4 \%(1 / 26)$ & $11 \%(2 / 18)$ & 0.59 \\
\hline & Overall & $80 \%(28 / 35)$ & $77 \%(20 / 26)$ & $89 \%(16 / 18)$ & 0.91 \\
\hline
\end{tabular}

acutely in two patients, subacutely in 69 patients and chronically in eight. Prior to RGS irradiation, 60 patients had significant headache, and 39 had significant seizures.

Irradiation was performed as radiosurgery with a RGS (Gamma ART 6000; American Radiosurgery, San Diego, CA, USA). The median dose was 20 Gy (range $=14-26 \mathrm{~Gy}$ ) and was administered as a single fraction. The dose was prescribed to the outer margin of the tumor representing the $50 \%$ isodose.

The major endpoint was best response with respect to relief of clinical symptoms, namely headache and seizures, during the follow-up period of 15 months following irradiation. When compared to symptoms at baseline prior to RGS irradiation, response was either complete (complete relief of symptoms), partial (partial relief of symptoms), stable disease (no change of symptoms) or progressive disease (increase of symptoms). Additional investigated endpoints included symptom relief at 15 months following RGS irradiation, the impact of the RGS irradiation on the size of the cavernoma at 15 months following irradiation (complete response, partial response, stable disease or progressive disease), assessed with magnetic resonance imaging (MRI) and bleeding within 2 years after RGS radiosurgery. The average time of followup was $54.9( \pm 21.9)$ months.

\section{Results}

Of the 60 patients who complained about significant headache prior to RGS irradiation, 10 patients (17\%) had a complete response, $49(82 \%)$ a partial response and one patient (2\%) had stable disease, respectively, as best response during the period of follow-up (Figure 1). At 15 months following RGS irradiation, a complete response was found in five patients (8\%), a partial response in $53(88 \%)$ and stable disease in two (3\%), respectively (Figure 2).

Of the 39 patients who experienced seizures prior to irradiation, $12(31 \%)$ had a complete response, $25(64 \%)$ a partial response and two (5\%) stable disease, respectively, as best response during the period of follow-up (Figure 3). At 15 months following RGS irradiation, a complete response was found in eight patients (21\%), a partial response in 23 $(59 \%)$ and stable disease in four (10\%), respectively (Figure
4). In addition, four patients (10\%) developed recurrent seizures after an initial post-treatment seizure-free interval.

With respect to the effect of the RGS irradiation on the size of the lesions at 15 months, a complete response was observed in five out of the 79 patients $(6 \%)$, a partial response (median decrease in size by $20 \%$ ) in 59 (75\%) and stable disease in $12(15 \%)$, respectively. In three patients (4\%), the lesion appeared larger than prior to RGS irradiation. Since a biopsy was not taken, it remained unclear whether this was true progression or pseudo-progression (radiation necrosis/swelling). In one patient (1\%) who developed recurrent clinical symptoms at 12 months following RGS irradiation true progression appeared likely. In the other two patients (3\%), the enlargement of the lesion was rated as pseudo-progression, since both patients showed improvement of their symptoms following RGS irradiation. Intracerebral bleeding following RGS radiosurgery occurred in five patients $(6 \%)$ within 2 years of irradiation. RGS radiosurgery-related acute toxicity was not observed.

In addition, the best response to RGS irradiation regarding headache, seizures and decrease of the cavernoma in size were compared for RGS doses of $<20$ Gy $(\mathrm{N}=35), 20 \mathrm{~Gy}$ $(\mathrm{N}=26)$ and $>20$ Gy $(\mathrm{N}=18)$. The results of this subgroup analysis are summarized in Table I. There were no significant differences in response related to RGS radiation dose.

\section{Discussion}

Symptomatic cerebral cavernomas are rare $(1,2)$. Complete neurosurgical resection is the standard treatment approach at many institutions. However, complete removal of such lesions is often not possible due to their location and risk (2). For these patients, non-invasive radiosurgery is a reasonable option, which is also widely used for the treatment of brain metastases (9-14). Several studies have shown that radiosurgery, either performed as linear accelerator-based or Gamma-Knife radiosurgery is a safe and effective treatment for cavernomas 


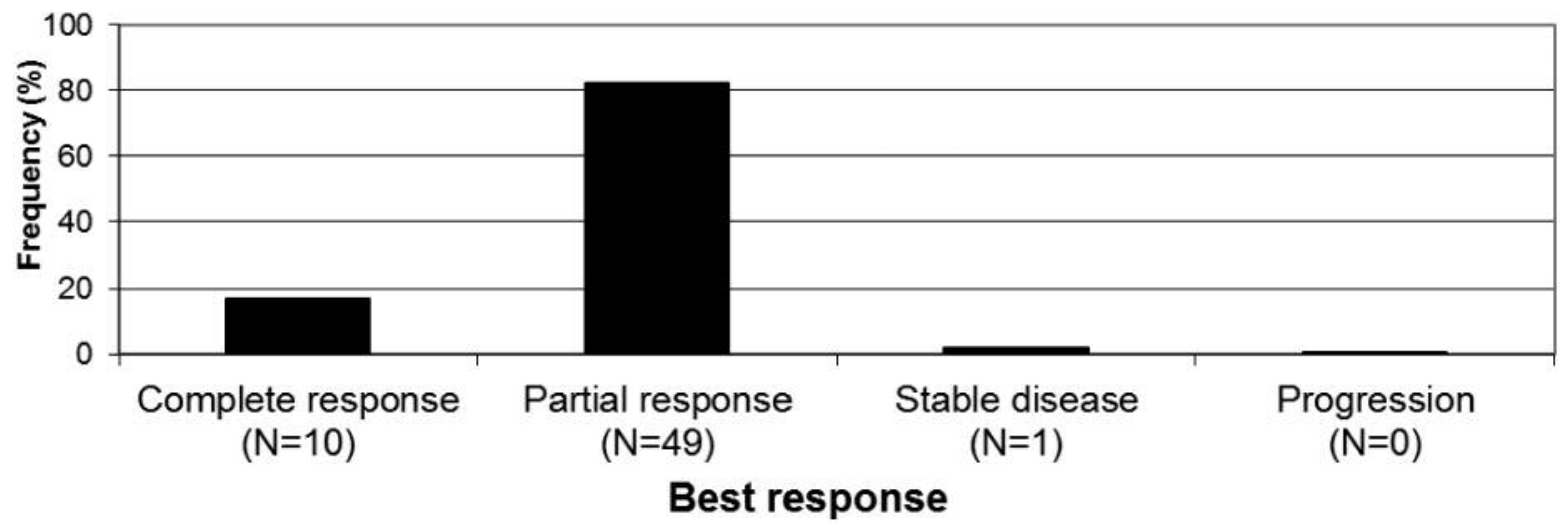

Figure 1. Headache: Best response after Rotating Gamma-System irradiation.



Figure 2. Headache: Response at 15 months after Rotating Gamma-System irradiation.

(1, 4-6). The classic Gamma-Knife was introduced in 1968 and linear accelerator-based radiosurgery in the $1980 \mathrm{~s}(7,15)$. The RGS technique was introduced in the late 1990s (8) but is available only at a limited number of institutions worldwide.

The present study is the second study to be reported that evaluated the role of RGS for cerebral cavernomas. RGS radiosurgery resulted in very high rates of symptomatic response of headache or seizures. Overall (complete or partial) response rates were $98 \%$ and $95 \%$, respectively. Decrease in cavernoma size was observed in $81 \%$ of patients. Bleeding after RGS irradiation occurred in $6 \%$ of the patients within 2 years. When comparing different RGS doses, dose had no significant impact on outcomes. In the only other study regarding the role of RGS radiosurgery for cerebral cavernomas $(\mathrm{N}=45)$, published in 2015 , the cohort received a median dose of $14 \mathrm{~Gy}$ (range=10-16 Gy). It reported postRGS irradiation bleeding rate of $4 \%$ within 2 years and decrease in cavernoma size in $38 \%$ of patients (16).
Prior to these two studies, several studies using linear accelerator-based radiosurgery or Gamma-Knife radiosurgery had been reported (17-22). Most of these studies reported results regarding the rate of bleeding within 2 years after radiosurgery. In 2010, Lunsford et al. reported a $21 \%$ bleeding rate in a series of 103 patients undergoing radiosurgery with a classic Gamma-Knife for a cerebral cavernoma (17). In a subgroup of this study including 68 patients with a brainstem cavernoma, the post-radiosurgery bleeding rate was $16 \%$ (6). A similar bleeding rate was reported by Park and Hwuang in 2012 for a series of 21 patients undergoing Gamma-Knife radiosurgery; the annual bleeding rate was $8.2 \%$ for the first 2 years (18). In another study including 45 evaluable patients treated with GammaKnife radiosurgery, the post-treatment bleeding rate was $7 \%$ (19). In 2014, a series of 39 patients who underwent Gamma-Knife radiosurgery for brainstem cavernomas with a median dose of 13 Gy was reported (20); within the first 2 


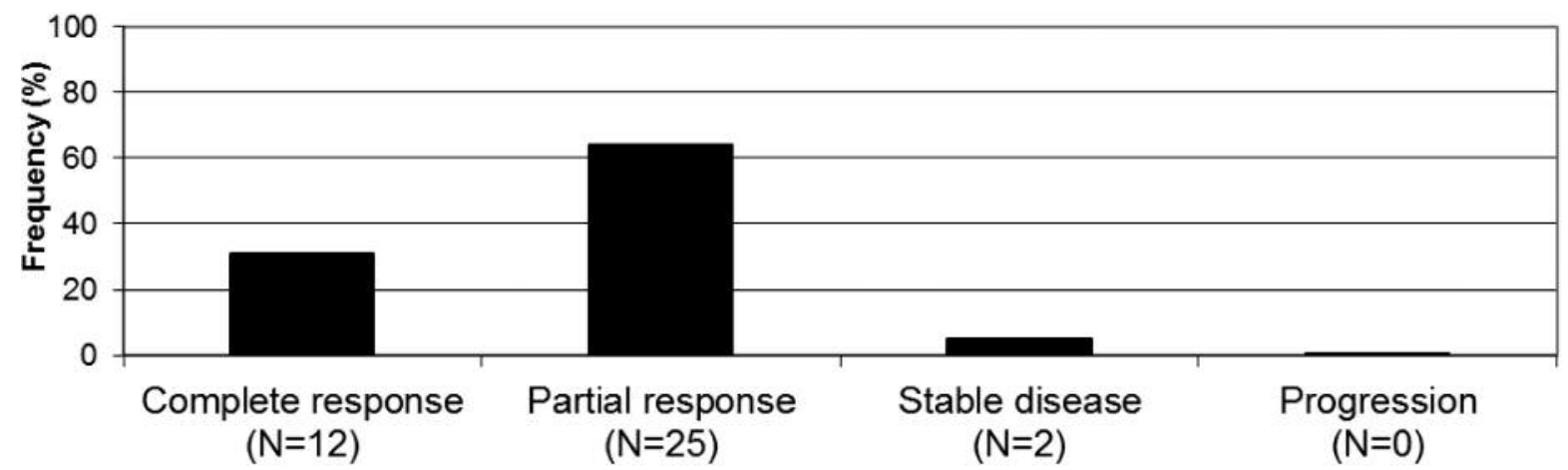

Best response

Figure 3. Seizures: Best response after Rotating Gamma-System irradiation.

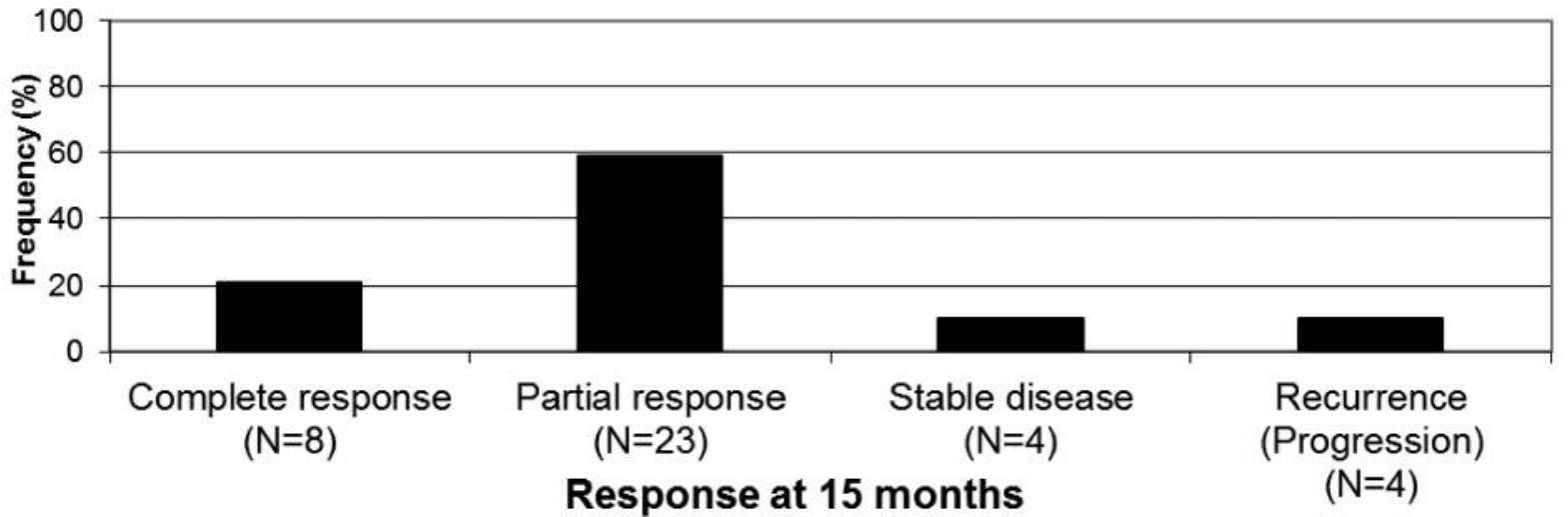

Figure 4. Seizures: Response at 15 months after Rotating Gamma-System irradiation.

years, bleeding occurred in five patients (13\%). In two other studies reporting on the post-radiosurgery bleeding rate, radiosurgery was performed with a linear accelerator $(4,21)$. The post-radiosurgery bleeding rate in the series of 14 patients reported by Fuetsch et al. was $33 \%$ (21). In the study of Sager et al., the rate was considerably lower, namely $6 \%$, after linear accelerator-based radiosurgery with median 15 Gy (range=10-20 Gy) (4). Summarizing the data from the literature regarding the bleeding rate within 2 years after radiosurgery, the bleeding rates after RGS radiosurgery of $4 \%$ and $6 \%$, respectively, appear lower than the bleeding rates in most other studies using classic Gamma-Knife radiosurgery or linear accelerator-based radiosurgery, which ranged between $6 \%$ and $33 \%($ median $=16 \%)(4,6,17-21)$.

In the studies from the literature, data regarding the other investigated endpoints from the present study were scarce. In the study of Sager et al. using linear accelerator-based radiosurgery, symptom relief (overall response) was observed in $64 \%$ of patients with headache and $55 \%$ of patients with seizures, (4). Liscak et al. reported symptom relief of seizures in $45 \%$ of a large series of 112 patients after Gamma-Knife radiosurgery with a median of $16 \mathrm{~Gy}$ (22). Decrease of the size of the cavernomas was observed in $53 \%$ of the patients. In the other study using RGS those if radiosurgery, decrease in size was observed in $38 \%$ of the cavernomas (16). Thus, the overall response rates observed in our present study were higher than those of other studies, revealing RGS radiosurgery to be an effective treatment for cerebral cavernomas. When comparing the results of the studies on radiosurgery of cerebral cavernomas, one should be aware that these studies were retrospective in nature and at risk of including hidden selection biases. However, cerebral cavernomas are uncommon and prospective studies are not expected soon. 
In summary, this study found that RGS radiosurgery can provide high rates of symptom relief and decrease in tumor size of cerebral cavernomas. Thus, RGS radiosurgery represents a reasonable alternative for these lesions, if complete surgical removal is not possible.

\section{Conflicts of Interest}

On behalf of all Authors, the corresponding author states that there is no conflict of interest related to this study.

\section{References}

1 Niranjan A and Lunsford LD: Stereotactic radiosurgery guidelines for the management of patients with intracranial cavernous malformations. Prog Neurol Surg 27: 166-175, 2013.

2 Mouchtouris N, Chalouhi N, Chitale A, Starke RM, Tjoumakaris SI, Rosenwasser RH and Jabbour PM: Management of cerebral cavernous malformations: from diagnosis to treatment. ScientificWorldJournal 2015: 808314, 2015.

3 Chalouhi N, Jabbour P and Andrews DW: Stereotactic radiosurgery for cavernous malformations: Is it effective? World Neurosurg 80: e185-186, 2013.

4 Sager O, Beyzadeoglu M, Dincoglan F, Uysal B, Gamsiz H, Demiral S, Oysul K, Dirican B and Sirin S: Evaluation of linear accelerator (LINAC)-based stereotactic radiosurgery (SRS) for cerebral cavernous malformations: a 15-year single-center experience. Ann Saudi Med 34: 54-58, 2014.

5 Lu XY, Sun H, Xu JG and Li QY: Stereotactic radiosurgery for brainstem cavernous malformations: a systematic review and meta-analysis. J Neurosurg 120: 982-987, 2014

6 Monaco EA, Khan AA, Niranjan A, Kano H, Grandhi R, Kondziolka D, Flickinger JC and Lunsford LD: Stereotactic radiosurgery for the treatment of symptomatic brainstem cavernous malformations. Neurosurg Focus 29: E11:1-6, 2010.

7 Leksell L: Stereotactic radiosurgery. J Neurol Neurosurg Psychiatry 46: 797-803, 1983.

8 Goetsch SJ, Murphy BD, Schmidt R, Micka J, De Werd L, Chen $\mathrm{Y}$ and Shockley S: Physics of Rotating Gamma Systems for stereotactic radiosurgery. Int J Radiat Oncol Biol Phys 43: 689696, 1999

9 Rades D, Huttenlocher S, Rudat V, Hornung D, Blanck O, Phuong PC, Khoa MT, Schild SE and Fischer D: Radiosurgery with 20 Gy provides better local control of 1-3 brain metastases from breast cancer than with lower doses. Anticancer Res 35: 333-336, 2015.

10 Janssen S, Dahlke M, Trang NT, Khoa MT and Rades D: Estimation of the six-month survival probability after radiosurgery for brain metastases from kidney cancer. Anticancer Res 35: 4215-4217, 2015.

11 Rades D, Dahlke M, Gebauer N, Bartscht T, Hornung D, Trang NT, Phuong PC, Khoa MT and Gliemroth J: A new predictive tool for optimization of the treatment of brain metastases from colorectal cancer after stereotactic radiosurgery. Anticancer Res 35: 5515-5518, 2015 .
12 Dziggel L, Dahlke M, Janssen S, Hornung D, Blanck O, Khoa MT, Schild SE and Rades D: Predicting the risk of new cerebral lesions after stereotactic radiosurgery (SRS) for brain metastases from breast cancer. Anticancer Res 35: 6793-6797, 2015.

13 Rades D, Dziggel L, Janssen S, Blanck O, Hornung D and Schild SE: A survival score for patients receiving stereotactic radiosurgery alone for brain metastases from breast cancer. Anticancer Res 36: 1073-1076, 2016.

14 Balducci M, Autorino R, Chiesa S, Mattiucci G, Pompucci A, Azario L, D'Agostino GR, Ferro M, Fiorentino A, Fersino S, Mazzarella C, Colosimo C, Frascino V, Anile C and Valentini V: Radiosurgery or fractionated stereotactic radiotherapy plus whole-brain radioherapy in brain oligometastases: A long-term analysis. Anticancer Res 35: 3055-3059, 2015.

15 Betti OO and Derechinsky VE: Hyperselective encephalic irradiation with linear accelerator. In: Gybels J, Hitchcock ER, Ostertag C, Rossi GF, Siegfried J and Szikla G (eds.): Advances in stereotactic and functional neurosurgery 6 . Acta Neurochirurgica (Suppl), Vol. 33, Springer, Vienna, pp. 385-390, 1984.

16 Fedorcsák I, Nagy G, Dobai JG, Mezey G and Bognár L: Radiosurgery of intracerebral cavernomas - current Hungarian practice. Ideggyogy Sz 68: 243-251, 2015.

17 Lunsford LD, Khan AA, Niranjan A, Kano H, Flickinger JC and Kondziolka D: Stereotactic radiosurgery for symptomatic solitary cerebral cavernous malformations considered high risk for resection. J Neurosurg 113: 23-29, 2010.

18 Park SH and Hwang SK: Gamma Knife radiosurgery for symptomatic brainstem intra-axial cavernous malformations. World Neurosurg 80: e261-266, 2013.

19 Lee CC, Pan DH, Chung WY, Liu KD, Yang HC, Wu HM, Guo WY and Shih YH: Brainstem cavernous malformations: the role of Gamma Knife surgery. J Neurosurg 117(Suppl): 164-169, 2012.

20 Kim BS, Yeon JY, Kim JS, Hong SC and Lee JI: Gamma Knife radiosurgery of the symptomatic brain stem cavernous angioma with low marginal dose. Clin Neurol Neurosurg 126: 110-114, 2014.

21 Fuetsch M, El Majdoub F, Hoevels M, Müller RP, Sturm V and Maarouf M: Stereotactic LINAC radiosurgery for the treatment of brainstem cavernomas. Strahlenther Onkol 188: 311-316, 2012.

22 Liscak R, Urgosik D, Simonova G, Vymazal J and Semnicka J: Gamma Knife radiosurgery of brain cavernomas. Acta Neurochir Suppl 116: 107-111, 2013.
Received May 2, 2017

Revised May 12, 2017

Accepted May 16, 2017 